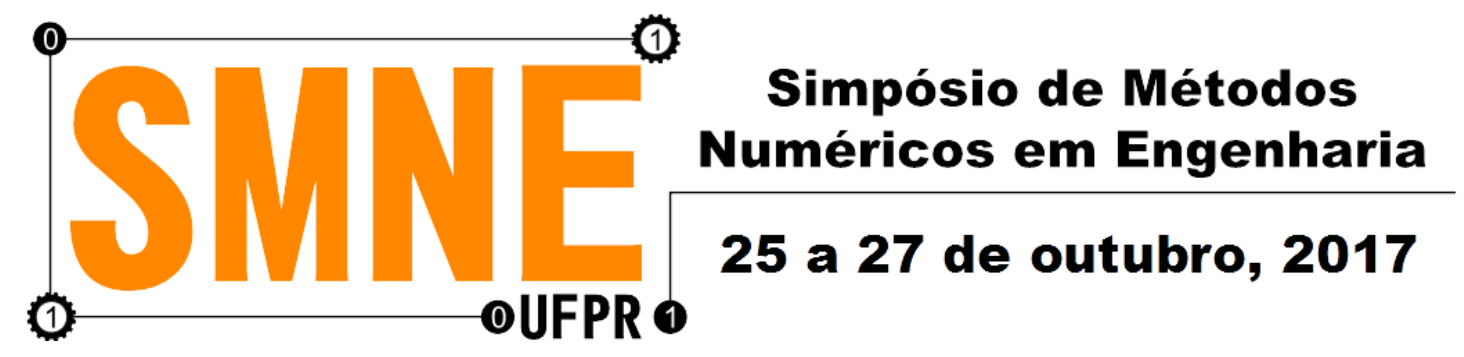

\title{
Aplicação de Heurísticas e Metaheurísticas na Composição de Séries Dodecafônicas
}

\author{
Déborah Baptista Pilato \\ PPGMN/ Departamento de Matemática \\ UFPR \\ Curitiba, Brasil \\ deborahpilato@hotmail.com
}

\author{
Paulo Henrique Siqueira \\ Departamento de Expressão Gráfica \\ UFPR \\ Curitiba, Brasil
}

Resumo - O objetivo deste trabalho é desenvolver, a partir do uso de heurísticas e metaheurísticas, meios de elaborar e obter compassos musicais que satisfaçam as caraterísticas do método de composição dodecafônico. Para isso, a série de notas utilizada é a cromática, optando-se por gerar compassos 2 por 4 e 2 por 2 a partir de mínimas, semínimas, colcheias e semicolcheias. A linguagem de programação escolhida para desenvolver os algoritmos é a linguagem Fortran, e o software MuseScore foi utilizado para representar as soluções obtidas na linguagem de partitura. Para que a aplicação das metaheurísticas fosse possível no contexto musical, os problemas aqui expostos foram reformulados de modo a tornarem-se equivalentes aos problemas característicos dessa outra área, como o Problema do Caixeiro Viajante e o Problema da Mochila, associando as notas musicais a objetos ou a cidades, permitindo que a resolução seguisse de maneira semelhante ao o que ocorre em tais problemas. Os resultados obtidos foram satisfatórios, pois os algoritmos retornaram compassos de acordo com o estipulado pelas restrições iniciais, mostrando que é possível compor as séries e compassos a partir de métodos heurísticos e metaheurísticos. Com as soluções obtidas em mãos, o objetivo é o de que estas sirvam de suporte ao compositor, que terá total liberdade de fazer alterações, descartar soluções que não lhe interessem e trabalhar com novos valores, buscando assim outras alternativas. Ou seja, os algoritmos desenvolvidos têm como principal objetivo servir de ferramenta no processo composicional, preservando sempre a criatividade e a liberdade presentes na criação.

Palavras-chave- Heurísticas; Metaheurísticas; Séries Dodecafônicas. Heuristicas; Metaheuristicas; Sêries

\section{INTRODUÇÃO}

Em um mundo tão complexo e rico, que permite constantemente o contato com novos conhecimentos e aprimoramentos, a inovação acaba sendo uma consequência lógica. Isso porque, sendo uma característica nata ao ser humano, a curiosidade leva-o a lugares antes nunca visitados, visto que o caminho gerado por perguntas e respostas bem estruturadas conduzem a novos horizontes, fortalecendo muitas vezes o poder de criação.

No meio empresarial, a produção e a competitividade caminham lado a lado, de modo que o desejo de liderar o mercado no qual atuam é o principal objetivo das companhias. Nesse sentido, inúmeros problemas surgem, sejam eles associados à produção, à logística, à distribuição e a inúmeros outros, sempre buscando um lucro maior ou então um menor custo.

Frequentemente, na modelagem de novos problemas e na busca por soluções encontram-se diversos obstáculos. Sejam estes devidos às restrições que possam existir, ou então pela dificuldade de combinar tais restrições com as variáveis existentes na formulação do problema. De uma forma ou de outra, o objetivo principal é sempre o mesmo: obter o melhor resultado possível. Nesse sentido, surge o conceito de otimização, que de acordo com [1] é "um mecanismo de análise de decisões complexas, envolvendo seleção de valores para variáveis (...)" cuja "intenção é 
encontrar a melhor solução, respeitando, se necessário, restrições de viabilidade (...)".

$\mathrm{Na}$ busca por tal solução surgem as Heurísticas e Metaheurísticas, onde as últimas, por exemplo, são inspiradas na física, biologia, ciências sociais, entre outros, e partem de métodos ou técnicas aproximativas que não garantem a solução ótima, mas chegam a soluções satisfatórias para determinados problemas.

Neste trabalho são propostas algumas aplicações de tais procedimentos na composição musical, baseando-se em condições pré-estipuladas, e buscando assim desenvolver uma ferramenta que permita ao compositor opções de sequências de notas e tempos de duração para as tais, que se adaptem às condições pré-definidas por ele.

Partindo do sistema dodecafônico, o objetivo deste trabalho é o de gerar sequências de notas partindo da escala cromática, de maneira que sejam respeitadas distâncias préestabelecidas entre duas notas consecutivas. Esta distância citada não é invariável, ficando a cargo do compositor e se adequando ao seu objetivo final. Além disso, a partir sequência gerada deseja-se criar compassos que as agrupem, formando assim pequenas séries musicais.

Para que essa sequência seja gerada e que os compassos sejam criados, esses problemas precisam ser modelados de modo a se adequarem aos métodos heurísticos e metaheurísticos. Dessa forma, as notas passarão a integrar um vetor solução, de modo que a cada uma delas foi associado um valor numérico.

A principal limitação encontrada no decorrer deste trabalho diz respeito à função responsável por gerar valores aleatórios que compõe a solução inicial no software Fortran. O que ocorre é que os valores não são de fato aleatórios, e sim pseudoaleatórios, de modo que ao seguirem distribuição uniforme ocorre a repetição de sequências, o que limita o campo de busca da solução ótima, uma vez que parte sempre do mesmo vetor inicial. Na tentativa de contornar esse problema foram utilizados para criação da população inicial valores gerados no software Excel e apenas lidos pelo software Fortran, bem como a criação de números aleatórios gerados a partir de dados fornecidos pelo usuário, como minutos e segundos atuais.

O presente trabalho está organizado em cinco partes, incluindo esta introdução. A segunda parte destina-se a abordagem dos métodos heurísticos e metaheurísticos utilizados no decorrer do desenvolvimento; a terceira parte apresenta conceitos básicos relacionados à área da música e que se farão necessários para a posterior compreensão dos resultados apresentados; a quarta parte apresenta de maneira simplificada a estrutura dos algoritmos que foram desenvolvidos, bem como os objetivos de cada um e os resultados obtidos; e finalmente a parte cinco - baseada em tudo o que foi mostrado -, apresenta considerações finais acerca do exposto, e faz recomendações para trabalhos futuros, que por ventura venham a dar continuidade ao que foi aqui iniciado.

\section{Heurísticas E MetaheurístiCAS}

As metaheurísticas são processos que visam a melhoria de uma solução, tendendo a solução ótima, e que consistem na aplicação de uma heurística subordinada em cada fase, a qual necessita ser adequada a cada problema em particular. Segundo [7], a metaheurística tem como primordial característica a capacidade de se evadir de ótimos locais dando flexibilidade às restrições da função objeto. As heurísticas fundamentam-se no aperfeiçoamento do movimento exercido, procurando um ótimo local, porém sempre oferecem a mesma solução se originadas de um mesmo ponto de partida, sendo assim limitadas.

$\mathrm{O}$ presente trabalho utiliza a heurística k-opt na resolução do Problema do Caixeiro Viajante (PCV) e a metaheurística Algoritmos Genéticos (AGs) na resolução do Problema da Mochila Compartimentada (PMC).

Conforme proposto por [6], o algoritmo k-opt visa a melhoria de uma solução a partir da troca de combinações dentro de sua própria vizinhança. Para isso, partindo de uma solução - obtida anteriormente a partir de um outro método - o método remove dela $\mathrm{k}$ arcos, e os substitui por $\mathrm{k}$ outros. O procedimento é uma generalização do método 2-opt, que apaga duas arestas de uma solução, transformando-a em dois sub percursos. Religam-se então os pontos formando uma nova solução, que substitui a anterior caso apresente melhores resultados.

Inspirados na Teoria da Evolução das Espécies de Charles Darwin, os AGs assemelham-se aos processos naturais de seleção, presentes em todos os grupos de seres vivos que ocupam nosso planeta. Tal teoria afirma que buscando a sobrevivência os indivíduos de uma mesma população competem entre si, e os mais aptos terão mais descendentes, propagando assim seus genes. Uma solução tem uma população inicial de indivíduos - geralmente gerados de maneira aleatória - que são chamados de "pais", e sobre ela aplicam-se os operadores genéticos, criando assim combinações, as quais são chamadas de "fillhos".

Os operadores genéticos citados são três: reprodução, cruzamento (crossover) e mutação, e nos problemas aqui discutidos são utilizados os dois últimos. O cruzamento utiliza dois indivíduos pais e combina seus materiais genéticos, gerando assim novos indivíduos, que herdam suas caraterísticas genéticas. Esta mistura é feita tentando imitar (em um alto nível de abstração) a reprodução de genes em células. Para efetuar o cruzamento entre os indivíduos são definidos aleatoriamente as posições, sendo geralmente utilizados 1 ou 2 pontos. Como é natural observar, em populações pequenas há grandes chances de perda de diversidade, o que gera um impedimento à melhora da solução. Já em populações muito grandes, há um alto custo computacional. Outro problema também associado à perda de diversidade é a ocorrência de incesto, e uma saída para isso é evitar o cruzamento entre indivíduos muito semelhantes.

Outra forma de contornar esse problema é a aplicação da mutação, que modifica aleatoriamente alguma característica do indivíduo sobre o qual é aplicada. Isso é importante 
porque ela ajuda a manter diversidade da população, garantindo que qualquer ponto do espaço de busca pode ser alcançado. Além disso, pode ser uma importante ferramenta no caso de estagnação na busca pela solução ótima, escapando de pontos de máximos locais.

Uma análise dos resultados deve ser feita após a aplicação dos operadores genéticos, concluindo se os indivíduos gerados por eles apresentam ou não uma melhora na busca por uma solução ótima. A função fitness (ou função objetivo) calcula o valor de aptidão de cada indivíduo, medindo quão próxima uma solução está do valor desejado. Por isso é essencial que esta função seja muito representativa e diferencie na proporção correta as más soluções das boas, para evitar que se fique inutilmente à procura do ótimo global. Quanto ao critério de parada do algoritmo, este pode ser definido de diversas formas. Como listado por [3] podem ser eles: "o alcance de um número máximo de gerações; solução ótima encontrada; perda de diversidade; ou convergência: nas últimas $\mathrm{k}$ gerações não houve melhora na aptidão.".

Já com relação à representação dos elementos, ela geralmente "se resume à utilização de cadeias (strings) de comprimento 1 , formadas por caracteres de um determinado alfabeto. O caso mais comum é o binário, onde o alfabeto é composto pelos símbolos 1 e 0 .”, como cita [2].

Clássico entre os problemas combinatórios, o Problema do Caixeiro Viajante (PCV) consiste em encontrar o roteiro de menor distância ou custo que passa por um conjunto de cidades, sendo cada cidade visitada apenas uma vez, e finalizando na cidade de origem. Já o Problema da Mochila (PM) surge na tentativa de resolver a seguinte situação: Imagine que você vai fazer uma viagem e para isso deverá levar alguns itens em sua mochila. No entanto, a mochila tem uma capacidade e pode ocorrer de não caber nela tudo o que você gostaria de levar. O mais natural então é pensar que terá que abrir mão de algumas em detrimento de outras, correto? A pergunta que surge agora é "o que devo levar?". O PM então deseja definir quais itens serão levados sem que a capacidade da mochila seja excedida.

Para que o Problema da Mochila Compartimentada (PMC) possa ser compreendido pode-se partir da ideia do PM acrescentando um detalhe. Imagine que dentre os itens que deseja levar há classes distintas entre eles, como por exemplo comidas, roupas, livros, entre outros, e que você deseja alocá-los em bolsos distintos dentro da mochila. Um custo $c_{k}$ é então associado a cada compartimento caso ele seja usado com algum item da classe $\mathrm{k}$ e o somatório de todos os compartimentos não pode exceder a capacidade total da mochila. Segundo [5], o PMC consiste em determinar as capacidades adequadas de cada compartimento e como estes devem ser carregados de modo que o valor de utilidade total seja máximo.

\section{NoÇÕES BÁSICAS DE COMPOSIÇÃO MUSICAL}

Falar sobre composição musical é o mesmo que falar sobre criar, inventar, reunir ferramentas, conhecimentos, experiências e sentimentos para transmitir algo novo, não sendo possível prever os resultados e impactos que isso causará no ouvinte. Isso porque a individualidade de quem ouve também é um fator importante nesse processo, de modo que suas vivências, lembranças e história influenciarão no resultado daquilo que chega aos seus ouvidos. Música é afeto, é sentimento, é sensação, e através de [4], afirma-se que o processo de criação é uma experiência emocional associada aos sentidos. Os elementos fundamentais (notas, compassos, figuras rítmicas, entre outros) e alguns métodos composicionais são abordados com o objetivo de garantir o entendimento do que foi desenvolvido nesse trabalho.

Notas musicais podem ser definidas como os elementos mínimos de um som. Quando uma corda vibra e as moléculas de ar ao seu redor se movimentam, essa movimentação ocorre na mesma vibração na corda. $O$ ouvido humano então capta tal vibração, processando-a e atribuindo a ela um som. O que ocorre então é que cada som diferente atribuído pelo cérebro representa cada uma das notas musicais. Chama-se de escala cromática a escala de 12 sons formada pelas 7 notas padrão da escala diatônica (Dó, Ré, Mi, Fá, Sol, Lá, Si) acrescidas dos 5 tons intermediários (com bemol e sustenido), formando então a sequência Dó, Dó\#, Ré, Ré\#, Mi, Fá, Fá\#, Sol, Sol\#, Lá, Lá\# e Si.

Já as figuras rítmicas indicam o tempo de duração de uma nota musical, e as mais usadas são a semibreve, a mínima, a semínima, a colcheia, a semicolcheia, a fusa e a semifusa. Há também uma relação de proporcionalidade entre elas, indicando que uma figura sempre vale metade da anterior. Ou seja, duas semínimas equivalem a uma mínima, por exemplo. Assim sendo, dentro dos compassos e dependendo da fórmula envolvida, cada figura rítmica assumirá um tempo de duração, que marcado na partitura sobre a posição da nota desejada representará o tempo que ela irá soar.

A figura rítmica que representa uma unidade de tempo é indicada logo no início da partitura, após o símbolo da clave. As oito figuras mais comuns foram vistas, e a cada uma delas associa-se o que é chamado de "fórmula de compasso". A fórmula de compasso é representada por dois números, um sobre o outro, como se formassem uma fração. $\mathrm{O}$ de cima (numerador) representa quantos tempos $\mathrm{O}$ compasso terá, e o de baixo (denominador) diz qual a figura rítmica que equivale a uma unidade. Assim sendo, o denominador "1" estará ligado a semibreve, "2" a mínima, "4" a semínima e assim por diante. Fato que explica-se pela relação de proporcionalidade existente entre as notas. Dessa forma, um compasso 3 por 4 indica que nele haverá 3 tempos e que a semínima vale 1 tempo.

Já com relação aos métodos de composição, até meados do século XIX predominavam as composições tonais, que pressupõem uma hierarquia entre as notas musicais, de modo que há um polo de atração e as notas comportam-se seguindo essa ordem estabelecida, com agrupamentos formados a partir da sobreposição de terças. Já no final do século, passou-se a observar um enfraquecimento dos 
vínculos com o polo atrativo, de modo que nem mesmo o retorno da tônica no encerramento da obra se fazia necessário. Essa mudança aos poucos deu origem a sistemas diferenciados, surgindo o que foi denominado sistema atonal.

Nesse sentido surgiu o dodecafonismo, que visa fornecer uma estrutura ao sistema atonal. Isso porque, devido à independência contida no processo (além da carência teórica) o método estava apresentando resquícios tonais, que é justamente o oposto objetivo inicial. Foi então que Shoenberg, um dos maiores nomes da época, desenvolveu a técnica de composição intitulada doze notas ou dodecafonismo, que tem como ideia principal que nenhuma nota pode ser repetida até que as onze demais tenham sido utilizadas.

Esse procedimento deu uma sensação de automatismo ao método, sendo criticado por limitar o processo de criação. No entanto, essa limitação é bem menos restrita do que os críticos afirmavam, uma vez que não havendo alteração quando transformada isomorficamente, as séries formadas podem ser utilizadas em qualquer de suas transposições ou em qualquer de suas transformações invariantes, isto é, na inversão, retrogradação ou retrogradação da inversão.

Assim sendo, o dodecafonismo trouxe uma estrutura que conferiu firmeza ao tipo de estrutura não tonal, induzindo, por outro lado, a ausência de significados harmônicos internos. Finalizando, para Shoenberg, a utilização da música atonal abriu as portas para a livre utilização da dissonância, que para ele é a essência desse processo.

\section{RESULTADOS}

O primeiro algoritmos trabalha utilizando as notas da escala cromática, de modo que deseja-se gerar uma sequência na qual duas notas consecutivas estejam no mínimo 1 e no máximo 3 tons de distância uma da outra. Dessa forma, é obtida uma série dodecafônica com características particulares quanto à distância entre duas notas consecutivas e aqui há uma relação entre o problema exposto e o PVC visto anteriormente. Para fazer essa relação, cada nota musical é considerada uma cidade, e o objetivo é o de percorrer todas as 12 cidades, sem repetir nenhuma delas. A diferença é que aqui não há interesse em percorrer a menor distância possível, e sim a distância de 1 a 3 entre uma cidade e outra.

Ao fornecer uma solução inicial, calcula-se a função objetivo associada e aplica-se o método 2-opt, visando a melhoria da solução obtida. Após aplicar o método, uma nova solução é obtida e sua função objetivo é calculada. Caso haja melhora, aceita-se a solução gerada e descarta-se a anterior, caso contrário, permanece com a solução anterior.

O método é então aplicado até que algum critério de parada seja atingido. Aqui foram implementados 3 deles, que são: valor ótimo alcançado; número máximo de iterações alcançado; e estagnação da solução por 5 iterações consecutivas.
Para a solução inicial fornecida, o algoritmo retornou a seguinte solução ótima:

$$
\text { C }
$$

Como é fácil perceber, a solução obtida satisfaz a condição inicialmente imposta, e portanto, é uma solução ótima para o problema.

$\mathrm{Na}$ sequência, o algoritmo 2 busca agrupar a sequência obtida em dois compassos 2 por 4 e dois compassos 2 por 2 , e para isso são utilizadas 4 figuras rítmicas: a semicolcheia, a colcheia, a semínima e a mínima.

É necessário levar em conta que o tempo de duração associado às figuras rítmicas varia de acordo com o compasso ao qual ela pertence. Em um compasso 2 por 4, por exemplo, a semínima equivale a uma unidade de tempo. Já no compasso 2 por 2 a mesma figura equivale a meia unidade.

Dessa forma, temos aqui uma relação entre o problema exposto e o PMC, visto que o objetivo é o de preencher cada bolso (compasso) com os objetos (notas) disponíveis, atribuindo pesos aos objetos de modo que seja possível preencher os bolsos de acordo com sua capacidade ao mesmo tempo que usam-se todos os objetos disponíveis.

A metaheurística AG é utilizada na resolução desse problema e utiliza dois operadores, primeiramente o cruzamento e depois a mutação.

O algoritmo inicia-se a partir da solução inicial, que é gerada de maneira aleatória. Logo após, os objetos são distribuídos entre os bolsos, respeitando a capacidade máxima de cada um. Uma vez que todos os objetos estão distribuídos, calcula-se a função fitness associada ao primeiro bolso (compasso), verificando se os pesos dos objetos que o compõe o completam exatamente ou não. Em caso afirmativo, segue-se para o próximo compartimento. Caso contrário, aplica-se o cruzamento em dois pontos, gerando assim dois novos indivíduos, que terão suas funções fitness calculadas. Com a nova população, formada agora por 4 vetores, seleciona-se os dois que apresentam os melhores valores, e compõe-se assim a nova solução. O algoritmo então segue, até que todos os compartimentos estejam completamente preenchidos.

Havendo a perda de diversidade e a posterior estagnação da melhora da função objetivo, aplica-se a mutação, que age em dois genes da solução obtida, alterando o valor correspondente. Dessa forma, uma nova solução é obtida, e se apresentar melhora no valor da função objetivo ela passa a ser a nova solução.

Aplicando o algoritmo obtém-se a seguinte solução:

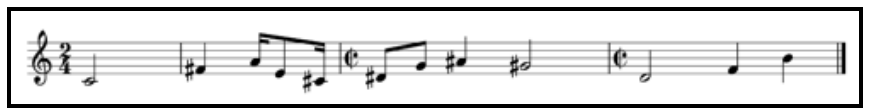

Figura 1. Solução representada na partitura

\section{CONClusÃo E SUGESTÕES}

A partir do que foi exposto e fazendo uma análise das soluções obtidas, verifica-se que foi possível chegar às 
soluções ótimas dos problemas propostos, gerando em cada um deles compassos formados por uma série dodecafônica, a partir das figuras rítmicas utilizadas.

Isso foi possível devido à relação criada entre os objetos musicais e os elementos característicos do PCV, PM e $\mathrm{PMC}$, já que ao associar as notas musicais às cidades, as figuras rítmicas aos pesos e o compasso à mochila, bastou adequar as funções objetivo para que o algoritmo pudesse ser desenvolvido e retornasse os valores obtidos. Além disso, em cada caso a solução obtida pôde ser representada na forma de partitura, o que demonstra de fato que o objetivo real foi alcançado.

Mesmo tendo alcançado os objetivos, para aprimorar a variedade dos resultados obtidos nesse trabalho recomendase que projetos futuros possam desenvolver melhores meios de obter os números aleatórios necessários ao processo, a fim de que se possa comparar os resultados. Mas mais importante que isso, sugere-se a criação de algoritmos que efetuem as inversões e transposições da série, combinandoos e testando as composições que daí resultarem.

Conclui-se reafirmando que em hipótese alguma desejase substituir o papel do compositor no processo de criação musical, e o que aqui foi desenvolvido visa apenas aplicar métodos heurísticos e metaheurísticos num campo pouco discutido e explorado, que é o da música.

\section{REFERÊNCIAS}

[1] SOARES, G. L. Algoritmos Genéticos: Estudo, Novas Técnicas e Aplicações. UFMG, Belo Horizonte, 1997.

[2] BENEVIDES, P. F. Aplicação de heurísticas e metaheurísticas para o problema do caixeiro viajante em um problema real de roteirização de veículos. UFPR, Curitiba, 2011.

[3] SIQUEIRA, P. H. Metaheurísticas e aplicações. UFPR, Curitiba, 2016.

[4] SANTOS, A. C. dos. Composição musical: estudos dirigidos para audiovisual. UFMT, Instituto de Linguagens, Cuiabá, 2008.

[5] CARVAlHO, R. Problema da mochila. Universidade Estadual de Campinas Instituto de Matemática, Estatística e Computação Cientifica - SP, 2015.

[6] LIN, S.; KERNIGHAN, B. An Effective Heuristic Algorithm for the Traveling Salesman Problem, 1973.

[7] CHAVES, A. A., (2003) - Modelagens Exata e Heurística para Resolução do Problema do Caixeiro Viajante com Coleta de Prêmios. Relatório Técnico - DECOM, Universidade Federal de Ouro Preto, Ouro Preto. 